\title{
Políticas de defesa e segurança para o Atlântico Sul no século XX
}

Manuel Domingos Neto

\begin{abstract}
Resumo: Este texto resulta de uma intervenção feita durante um evento promovido pelo Observatório das Nacionalidades. Ao discutir a defesa do Atlântico Sul, procuro debater as ideias predominantes nas análises acadêmicas do campo das Relações Internacionais e dos Estudos de Defesa. Parto do princípio de que, no pano de fundo destes domínios, a produção literária brasileira é dominantemente conservadora e não antevê uma atuação autônoma e soberana do Estado. Ao final, alinhavo algumas proposições de interesse do Brasil, relativamente à defesa do Atlântico Sul.
\end{abstract}

Palavras-chave: Defesa

Segurança; Políticas Públicas; Brasil.

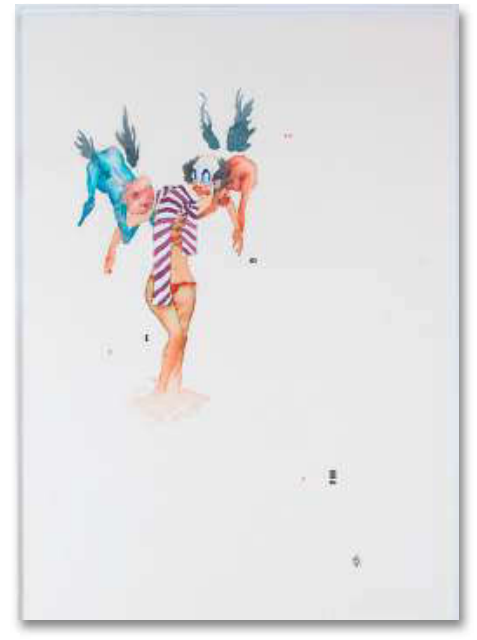

\section{Defense and Security Policies for the South Atlantic Region in the 21st Century}

\section{Manuel Domingos Neto}

Manuel Domingos Neto Pesquisador com pós-doutorado na École des Hautes Études en Sciences Sociales e professor-visitante da Universidade Estadual do Piauí. mdomingosneto@yahoo.com.br.
ABSTRACT: This paper resulted from a contribution presented during an event promoted by the Nationalities Observatory research group. In this occasion, I tried to discuss prevalent ideas in the academic analysis on International Relations and Defense Studies. My starting argument was that the extremely conservative literary production on these matters do not signalize to a conception of an autonomous and sovereign performance of the Brazilian State.

Keywords: Defense; Security; Public Policies; Brazil.

ReCEBIDO EM: $0 \overline{8 \text { SetEMBRO De } 2015}$ Aprovado em: $15 \overline{\text { DE OUTUBRO DE } 2015 .}$ 
Manuel Domingos Neto

\section{GUERRA E DOMÍNIO IMPERIALISTA}

Nesta reflexão sobre as políticas de defesa para o Atlântico Sul, nadarei contra a maré: tomo a guerra como o dado central do mundo em que vivemos e estranho o estudo da política internacional que faz pouco caso de seus fundamentos, dos guerreiros, dos produtores de armas e das ideologias que disseminam.

A guerra e a preparação para a guerra balizam a vida e o amanhã de Estados e sociedades. Essa afirmação seria dispensável: ninguém, em sã consciência e com conhecimento de causa, acreditaria no contrário. O pensamento dominante nas análises das relações internacionais, contudo, valoriza a "estabilidade" e a "ordem", como bens maiores e como os mais elevados objetivos de indivíduos, sociedade e Estados, contradizendo capciosamente essa elementaridade e disseminando pressupostos inconsistentes.

A "estabilidade" e a "ordem" representam a superação ou a ausência da guerra; são ideias amparadas na perspectiva da paz sustentável, ou seja, no fim da história tal qual a conhecemos ou na mudança das condições da humanidade. A estabilidade representaria a extinção do preparo contínuo para a guerra, algo que os homens conhecem, desde os primeiros registros da vida humana.

Analiso a política internacional, baseado em princípio segundo o qual o confronto sangrento e a sua preparação constituem a normalidade e não a excepcionalidade, nas relações entre sociedades e Estados. Considero que a guerra e a preparação para a guerra não decorrem de circunstâncias especiais, extraordinárias, resultantes de "fracassos", "erros", "má condução da política", "equívocos", "desvios" ou "habilidades". Explicações deste tipo negam que as autonomias nacionais podem se materializar sem confrontos e que as carnificinas integram a experiência humana.

Acredito que tanto o derramamento de sangue como o seu preparo estão no DNA das relações entre sociedades e Estados. Aliás, uso com cuidado as palavras "belicismo" e "pacifismo": nenhuma delas exprime, por si, algo de positivo ou negativo. A "paz" resulta da imposição da vontade do mais forte; a postura bélica resulta da insubordinação do dominado e da necessidade do dominador de manter o status quo. O valor intrínseco de cada 
um destes termos é delimitado pelos propósitos políticos firmados em circunstâncias históricas definidas. Somente as circunstâncias e os prismas dos atores-observadores permitirão creditar valor inequívoco a estas palavras.

Em todas as "matrizes teóricas" dos estudos classificados como de "Relações Internacionais", a utopia kantiana marca presença, servindo aos propósitos do dominante. Os que aceitam a dominação absorvem as noções de "estabilidade" e "ordem" como justas e verdadeiras. Por sua vez, os que repelem de fato a dominação certamente não podem admiti-las como algo indiscutivelmente desejável.

Quem domina sabe que precisa de tecnologias cada vez mais avançadas e que o carro-chefe da produção de novidades que animam o mercado é o artefato guerreiro, produzido por um complexo formado por múltiplos e intrincados interesses. No passado, este complexo foi denominado de "indústria de guerra"; depois, de "industrial-militar". Agora, prevalece a expressão "indústria de defesa".

A competição econômica e a inserção de um Estado na cena global estão diretamente relacionadas aos resultados de esforços de inovação em ciência e tecnologia e absorção das novidades pela indústria. Esta absorção torna rentáveis os investimentos em pesquisa e inovação voltados para a defesa. O capital rentista, por sua vez, está presente em toda a cadeia de relações que leva um Estado à condição de mando ou subordinação.

Aqui, estamos diante de um quadro aparentemente contraditório. Se o detentor do capital necessita da guerra, que aquece mercados, demanda, por outro lado, uma base jurídica estável, sem a qual os negócios não se efetivariam. Ocorre que a dinâmica da disputa capitalista conduz a conflitos que negam leis e acordos e engendra continuamente novos arranjos institucionais.

Desde os jusnaturalistas, sabemos que sem "contrato" não há comércio. Um determinado quadro jurídico-institucional de vasto alcance é uma exigência para a realização do capital. O respeito aos acordos e leis internacionais são pressupostos para os negócios internacionais, mas o desrespeito ao legislado e ao acordado é também prática necessária e recorrente, tanto por parte das 
Manuel Domingos Neto

potências que monopolizam a produção de armamento quanto pelos que se movem por aspirações libertárias e autonomistas.

Outro aspecto sobre o qual chamaria a atenção é que o debate sobre a defesa do Atlântico Sul exige ter em conta os termos "imperialismo" e "colonialismo". Dos dois lados do oceano, estamos lidando com ex-colônias que não lograram autonomias razoáveis. A América do Sul, mais "ocidentalizada", está longe de se equiparar, em termos econômicos e militares, às potências do "Norte"; a África sequer curou as sequelas das guerras de libertação e vive em permanente instabilidade; seus conflitos internos, inclusive, são alimentados pelas disputas dos países hegemônicos.

Assim, designo como "imperialismo" os movimentos de projeção de força da potência que domina ou quer dominar além de suas fronteiras. Alguns certamente considerarão tal postura como panfletária, radical, limitada, simplista e outras coisas mais. Podem arguir que a dominação não ocorre apenas através da violência física e que a defesa das fronteiras de um Estado exige cuidado com o chamado "entorno estratégico".

É obvio que o uso da força sobre Estados e sociedades se dá em combinação com variados recursos e apelos, notadamente os acordos econômicos, mas a subalternidade é explicitada, através da inferioridade militar e da incapacidade de estabelecer alianças capazes de impor resistência ao mais forte.

Na verdade, as objeções ao emprego do conceito "imperialismo" quase sempre são semânticas e voltadas para o encobrimento de um princípio, segundo o qual o dominador impõe suas determinações pela força.

Um aspecto usualmente encoberto da política imperialista (inclusive, pelos dominados) é o fato de que a dominação reforça a tendência do dominante de acumular vantagens na competição internacional, devido ao financiamento indireto de sua capacidade militar. A guerra alimenta o desenvolvimento capitalista ao promover novidades nos domínios científico, tecnológico, industrial, político e societário.

Quanto ao "entorno estratégico", trata-se de uma faixa de segurança que, dependendo da vontade e da capacidade militar de uma potência, pode ser do tamanho do mundo. Assim ocorreu 
Políticas de defesa e segurança para o Atlântico Sul no século XX

com o Império Britânico e, depois da Segunda Guerra Mundial, com a potência hegemônica, os Estados Unidos. A França, que nunca abdicou de veleidades imperiais, define um entorno que abrange diversos continentes.

Ao longo do século XX, potências com variadas capacidades econômicas mantiveram guerras prolongadas para manter domínios distantes, seja sob o formato de "colônias", "protetorados", "áreas de influência" ou "territórios de além-mar".

Nos termos do mundo competitivo que conhecemos, não há sinais de arrefecimento do afã imperialista. O imperialismo, portanto, é alimentado pela necessidade de garantir consumidores de mercadorias e serviços, assim como fontes regulares e seguras de matérias-primas a baixo custo e contratadores de empréstimos e compradores de tecnologia.

Os antigos sistemas coloniais ruíram ao longo do último século, mas o sumiço de um figurino institucional não anula a prática da dominação exercida, em detrimento da soberania de Estados mais débeis. Variados procedimentos foram criados para a manutenção da dependência da maioria dos países em favor de alguns poucos Estados com maior capacidade econômica e militar.

Por "colonizado", designo o dominado que não aspira nem se empenha solidamente em romper com seus variados laços de subordinação. Não coloco Franz Fanon em desuso: o colonizado tem medo e abdica da possibilidade de pensar de modo próprio; adota, conscientemente ou não, os fundamentos do modo de pensar do dominador.

Cabe examinar se, no rol dos colonizados, pode ser incluída a maioria dos professores de Ciência Política e Relações Internacionais, diplomatas, militares, jornalistas, políticos e juízes brasileiros, independentemente do fato de abraçarem bandeiras de reformas sociais e se acreditarem defensores da pátria. Para efeito, um bom teste seria medir o apreço que demonstram às noções de "ordem" e "estabilidade" em suas considerações sobre as relações entre os Estados.

A rápida expansão, nos últimos anos, dos estudos das Relações Internacionais no Brasil espelhou bem mais que a projeção internacional adquirida pelo país, através de iniciativas orientadas 
Manuel Domingos Neto

pela vontade de autonomia. Refletiu a vaga conservadora que, nas últimas décadas, contaminou a intelectualidade acadêmica, cada vez mais orientada pela forma de pensar das universidades dos países dominantes. É curioso observar como nenhum estudo ou nenhuma disciplina de Relações Internacionais obtém reconhecimento acadêmico, caso não esteja rigidamente lastreada por ideólogos anglo-saxões.

A maior parte da produção literária brasileira, nesta nova área do conhecimento, fundamenta-se em teorias e procedimentos reconhecíveis pelo desiderato imperialista e alimenta, em últimos termos, o discurso justificador do exercício da hegemonia mundial. A adoção acrítica de teorias na área de Ciências Políticas, das quais derivam as Relações Internacionais, gera consequências sobre a inserção do Estado e da sociedade na cena mundial, na medida em que contribui para selar a condição de desterrados em terra própria.

No que tange aos militares brasileiros, algumas teses, inclusive as de verniz patriótico, sustentadas nas principais escolas do Exército, da Marinha e da Força Aérea, parecem textos encomendados pelo Pentágono. As ideias embutidas nos documentos que orientam a defesa nacional não escondem velhas e inócuas práticas de busca de autonomia tecnológica, a partir de parcerias com os detentores de tecnologia de ponta, e negam o que os próprios militares afirmam costumeiramente: que detentores de tecnologia sensível não a cedem a outrem, para não compartilhar poder.

Já entre os diplomatas e parlamentares, não há posições tão monolíticas. Ideologicamente, a corporação diplomática é menos seletiva que a militar e não requer a mesma "unidade de doutrina". Por sua vez, a composição dos parlamentos enseja forçosamente pontos de vista diferenciados, mas os parlamentos pouco ou nada interferem nas definições estratégicas da Defesa. Quanto aos juízes, seu despreparo para os negócios da defesa é demonstrado pela necessidade de cortes corporativos. Tribunais militares eximem o juiz comum de lidar com realidades absolutamente estranhas à sua formação profissional e os editorialistas dos grandes jornais, que exprimem a tendência dos setores politicamente hegemônicos, 
Políticas de defesa e segurança para o Atlântico Sul no século XX

parecem viver uma permanente competição de ventríloquos e assumem-se arautos das ideias dos centros hegemônicos. Portanto, não há diferenças substanciais na forma de pensar da grande imprensa.

\section{O MASCARAMENTO DA ATIVIDADE GUERREIRA}

Verifiquemos as motivações para a pouca atenção dos especialistas em Relações Internacionais, no que diz respeito à guerra e aos guerreiros.

É sabido que ninguém explicou ainda, de forma definitiva, a origem do Estado, mas qualquer tentativa de explicação razoável destacará a guerra como uma das motivações para a sua emergência e consolidação. As ideias de cooperação e harmonia entre as sociedades emanam da inevitabilidade e da dureza de confrontos sangrentos. Os homens veneram e odeiam a guerra. Tratei desta temática em meu ensaio o Militar e a Civilização (DOMINGOS NETO, 2005).

A partir de Maquiavel, o pensamento moderno consagrou a ideia de que o Estado é o exercício do domínio sobre a sociedade. Somente ao Estado cabe o monopólio da violência. A consolidação do Estado, assim como a sua permanência, requer o uso da força. Ao Estado cumpre se preparar para a guerra. Quando isso não ocorre, por quaisquer que sejam os motivos, a sua existência passa a depender de potência estrangeira. Na condição de protetorado, obviamente, sua autonomia é resumida.

Assim sendo, nesta reflexão, temos em conta o Estado que reclama soberania, ou seja, aquele que se prepara para a guerra.

Como a guerra é sempre uma decisão de quem exerce ou quer exercer o poder (aliás, a guerra é a expressão mais acabada do exercício do poder, pois é o seu resultado que define o poderoso), o mascaramento de suas razões efetivas integra a estratégia guerreira, que, do contrário, desmobilizaria homens e mulheres para matar e morrer. Repito aqui uma banalidade: na guerra, a verdade é sempre a primeira a ser sacrificada pelo tanto que envolve de sagração de si e demonização do outro. Quem lograria envolver coletividades em banhos de sangue sem apresentar 
Manuel Domingos Neto

motivos sacrossantos, o que pressupõe a criminalização do inimigo?

O mascaramento da razão guerreira será sempre rebuscado. É compreensível que o senso comum seja engolfado por artimanhas políticas e discursos artificiosos; difícil é aceitar o seu brando acatamento pelo pensamento acadêmico.

No discurso do Estado, hoje, estão em pauta a "defesa da democracia", dos "direitos humanos" e do "meio ambiente". Os que conhecem minimamente a guerra sabem que ela se trata de um fenômeno que nega radicalmente tudo isso. Na guerra, não há democracia, direitos ou preocupações ambientais; a guerra suspende quaisquer veleidades de respeito aos princípios e regulamentações interpostas à vontade de submeter o outro. Quando o fuzil fala, o resto cala.

A persistente tentativa de mascarar essa razão guerreira tem seu lado civilizatório: revela a vergonha pela eliminação consciente e programada do semelhante. Benedict Anderson (2011) assinala que os antigos Ministérios da Guerra passaram a ser designados como Ministérios da Defesa, depois da Segunda Guerra Mundial, sem que suas naturezas institucionais tenham sido alteradas. Acompanhando Anderson, o mal-estar foi explicitado pela negação.

Quem negaria que o sistema internacional construído nos últimos séculos teve como esteio a competição e não a colaboração? O "tempo de paz", expressão costumeira no pensamento de estrategistas, designa o sistemático, persistente e cada vez mais complexo preparo de novas carnificinas. Aliás, o uso do conceito "estabilidade" como valor universal indiscutível, tal como ocorre entre os estudiosos das Relações Internacionais, não passa de um artifício para negar a natureza nada dignificante das "ordens internacionais" estabelecidas até o presente.

A competição capitalista tem como necessidade e horizonte o derramamento de sangue, não a convivência pacífica entre atores que se respeitem mutuamente. Sem crises periódicas, disputas violentas por mercados, imposições de regras aos povos do mundo, sem "ordem internacional", não haveria desenvolvimento capitalista. 
Ao mascarar a razão guerreira como elemento-chave das relações internacionais, os teóricos do imperialismo e seus seguidores mal disfarçados pretendem negar a vontade de domínio do mais forte e o direito do menor de desafiar o maior. As teorias das Relações Internacionais querem ignorar que a "ordem" seja rigorosamente um sistema do agrado de quem detém a força. A falaciosa expressão "comunidade internacional", empregada com desfaçatez e sem aspas, exprime a imposição da vontade combinada dos maiores sobre os menores.

A ideia de que a guerra está no cerne da experiência humana e que se mostra vigorosa na modernidade contradiz noções assimiladas pelos que lidam com negócios internacionais. Todos, normalmente, operam com a possibilidade de "harmonia", "respeito", "boa convivência" e, enfim, "paz" entre Estados e sociedades. Esses conceitos estão presentes em estudos e nas práticas da política internacional; entremeados, ensejam relatos aceitáveis entre os atores da cena global, mascarando a razão guerreira que preside a orientação dos poderosos.

Tenho chamado de "razão guerreira" os princípios que alimentam aquilo que a linguagem militar designa como "projeção de força", que é a capacidade de impor a vontade, seja pela dissuasão seja pelo uso da violência.

É lugar comum dizer que o restrito círculo dos gigantes das finanças, da indústria e dos serviços orientam as políticas públicas, notadamente as políticas externas. Isso, porém, deve ser relativizado: os aparelhos militares têm dado as cartas com crescente desenvoltura. Não decidem, em última instância, mas sempre são levados em conta. Entre as potências que ditam a "ordem mundial", a decisão de guerrear dificilmente é monocrática.

Na guerra e em seu preparo, a corporação militar atinge um nível de especialidade e de autonomia que lhe permite, em algumas circunstâncias, decidir à revelia da sociedade e do poder político. O mundo industrial e financeiro sabe disso, passando a operar afinado com o estamento militar. Vivemos um tempo em que pipocam escândalos de indistinção entre o interesse público e o interesse privado - são os espetáculos da falsa moralidade. O estudioso minimamente avisado sabe da promiscuidade das 
Manuel Domingos Neto

relações entre produtores de armamento e agentes do Estado, em que pese tais relações serem protegidas como segredo de Estado.

Falando acerca do medo, Eduardo Galeano (2001) disse que o militar teme a falta de armas e as fábricas de armas temem a falta de guerras. O grande aliado da corporação militar é o sistema industrial dedicado à produção de material de guerra, melhor chamado de indústria de defesa. Esse sistema opera também na fabricação de guerras.

O que é efetivamente mascarado é o domínio do mais fraco pelo mais forte. Não há desigualdades, exploração, submissão de povos - situações, enfim, inerentes ao desenvolvimento capitalista - sem brutalidades. Isso é o que se pretende mascarar.

Por tudo isso, considero que, para analisar com propriedade as relações internacionais, o xadrez geopolítico e as políticas de defesa e segurança, é fundamental o conhecimento da guerra, das corporações militares e de seus integrantes. Não cabe também esquecer os industriais e os prestadores de serviço relacionado à atividade guerreira. Trata-se de um desafio considerável. Estamos falando de instituições de alta complexidade, herméticas, legalmente protegidas e que tendem a ser cada vez mais autônomas no seio do aparelho estatal.

Não obstante a relevância do conhecimento das Forças Armadas para a compreensão dos processos sociopolíticos, é intrigante o esforço empreendido para que elas persistam como grandes caixas pretas.

No âmbito do Programa Álvaro Alberto, o projeto desenvolvido pelo Observatório das Nacionalidades encara o desafio de oferecer alguma luz sobre os sistemas de defesa do Atlântico Sul, referentes às relações Brasil-África. Acrescentaremos algo de substancial nesta matéria, se desobedecermos aos cânones e às práticas das chamadas Relações Internacionais.

\section{SOBRE O ATLÂNTICO SUL E A ÁFRICA}

Os que se debruçam seriamente sobre os espaços designados "Atlântico Sul" e "África" se deparam inicialmente com as dificuldades de suas delimitações físicas. Onde começam e terminam tais espaços? Em seguida, surgirão as perguntas: o que 
Políticas de defesa e segurança para o Atlântico Sul no século XX

a África tem a oferecer ao mercado e quais as condições em que se travarão as disputas por suas riquezas?

O continente africano talvez seja o espaço do planeta mais fechado à observação estrangeira. A África fascina o olhar "ocidental" pelos mistérios que a envolvem.

Do ponto de vista geográfico, a maior parte do continente fica no hemisfério norte, mas o usual é a sua inclusão no "Sul", um termo vago, carregado de estigma, empregado para caracterizar o que se enquadra de forma subordinada no mundo industrializado. Quanto ao "Atlântico Sul", trata-se de um espaço que se confunde não apenas com o Norte, mas com outros oceanos, em particular o Pacífico e Índico. Desde sua origem, o Tratado do Atlântico Norte, mesmo voltando suas baterias contra o comunismo, contemplou a atuação no Sul. Após a Segunda Guerra Mundial, as revoltas africanas contra o colonialismo foram um capítulo destacado do chamado confronto "Ocidente-Oriente".

O continente africano sempre foi importante para a humanidade, inclusive sob o aspecto geopolítico. O interesse pelo domínio deste espaço não se restringiu à exploração de músculos humanos e matérias-primas è conquista de mercados consumidores. Diversos pontos geográficos africanos são decisivos para as transações mundiais. Hoje, o bloqueio militar de tais pontos paralisaria boa parte dos negócios internacionais e provocaria o descontrole da distribuição de mercadoria fundamental nas articulações geopolíticas: as fontes energéticas. O Nordeste africano faz fronteira com a área mais conflitada, desde a descoberta de suas jazidas de petróleo: o Oriente Médio. Os mercadores europeus que demandam o Oriente terão seu caminho encurtado arrodeando a África.

Ocontinentenãoéumaunidade,éummosaicoespetacularmente multifacetário de culturas, etnias e ambientes físicos. Mesmo sabendo disso, os "ocidentais" insistem em homogeneizar o vasto espaço africano. A tendência do capitalismo é a difusão de instituições mundialmente padronizadas, de forma a favorecer os negócios. As organizações internacionais mais influentes, como o Banco Mundial (BM) e o Fundo Monetário Internacional (FMI), atuam na difusão destes padrões. 
Manuel Domingos Neto

O "Ocidente" está presente na África há muito tempo, sempre de forma agressiva e flagrantemente deletéria. É vasta a literatura que relata tal presença. O "Ocidente" se manifesta hoje, decisivamente, através de elites nacionais africanas intelectualizadas. Refiro-me aos que conduziram a luta anticolonial e hoje protagonizam a construção de Estados nacionais. Este tipo de Estado é festejado como resultante do processo civilizador, mas a sua construção na África revela em plenitude o seu teor sombrio, sanguinolento e impiedosamente destrutivo.

A "ocidentalização" da África é crescente e, no sentido da expansão capitalista, inevitável. A luta pela construção de nacionalidades legitimadoras de Estados implica na destruição de crenças, valores e práticas ancestrais, assim como requer a construção de memórias coletivas distanciadas de tradições vivas e palpitantes, como nos revelam os exuberantes ficcionistas africanos que escrevem em línguas europeias.

Do ponto de vista político, princípios e valores inerentes aos Estados industrializados, com destaque para a "democracia", os "direitos humanos" e o "respeito ao indivíduo", são rigorosamente incompatíveis com a preservação de traços culturais próprios dos povos africanos.

Outra incompatibilidade é o estabelecimento de fronteiras terrestres. Muito já foi escrito sobre os efeitos traumatizantes da divisão geopolítica da África, a partir dos acordos estabelecidos entre as potências coloniais, desde o final do século XIX. Não há razoabilidade na divisão política do continente e isso alimenta permanentemente suas tensões internas.

Menos conhecida é a ancestral convivência dos africanos com o meio ambiente. Neste domínio, a ocidentalização da África, além de provocar irreversíveis mudanças no meio físico, destruirá saberes preciosos.

Com frequência, a literatura se refere ao mundo colonizado como um grande conjunto, incluindo as Américas, a África e partes do continente asiático, mas o processo de colonização africana não pode ser facilmente comparado. Nenhum outro território foi agredido com o translado forçado de sua população, ao longo de séculos. A chamada diáspora africana embraça a Europa e todo o continente americano. Os africanos foram espalhados pelo 
mundo e passaram a nutrir uma onda sem fim de conflitos étnicos e sociais.

Outra dificuldade na comparação entre as experiências de colonização é o fato de os africanos terem resistido com sucesso à invasão europeia. A África viveu a experiência colonial, mas nunca foi de fato colonizada através de ocupações, como no caso da América. Por séculos, o estrangeiro ficou apenas na periferia. A penetração da força colonial tornou-se possível, apenas, com os meios técnicos disponíveis na Segunda Guerra Mundial.

O capitalismo ocidental drenou permanentemente riquezas africanas. Atualmente, a África é saqueada em muitos bilhões de dólares por meio de pagamentos do "serviço da dívida", de lucros de investimentos de toda ordem e da exploração das riquezas naturais. A África financia as classes dominantes ocidentais, através do baixo preço das matérias-primas, dos baixos salários recebidos pelos africanos e da devastação de seu meio ambiente.

Esse continente foi e persistirá objeto de disputa sangrenta, porque tem o que o desenvolvimento do capitalismo precisa: energia, minérios, terra para produção de alimentos, biodiversidade, criatividade e um mercado consumidor em rápida expansão.

Por tais motivos, qualquer estudo sobre a defesa do Atlântico Sul no contexto da cooperação Brasil-África deveria partir da análise das propensões imperialistas dos países industrializados e de seus grandes dispositivos militares. Atenção especial deve ser dada às orientações dos Estados Unidos: a África sempre foi objeto de intervenção europeia, mas o protagonismo estadunidense no continente é cada vez mais claro, correspondendo, inclusive, à avassaladora presença chinesa.

No reordenamento geopolítico em curso, com a ascensão da potência asiática, a reintrodução da Rússia como protagonista global e o início de uma presença brasileira sobre o continente africano, as iniciativas estadunidenses são abrangentes, derramando-se por todo o continente, através de pequenas bases militares, projetadas para rápida expansão. Dessa maneira, do ponto de vista da defesa do Atlântico Sul, o principal dado a ser retido pelo Brasil é o crescimento da disputa sino-estadunidense na África. 
Manuel Domingos Neto

Dadas as fragilidades e incertezas inerentes à formação dos Estados nacionais africanos, não fica descartada a possibilidade de, ao cabo de algum tempo, surgirem ditaduras filo-americanas, replicando-se a experiência vivida na América Latina, ao longo do século XX.

\section{DESAFIOS AO ESTADO BRASILEIRO}

A política brasileira para o AtlânticoSuldeveser necessariamente multifacetária e implementada por diferentes instrumentos de Estado. Em que pese ser uma das maiores economias do mundo, o Brasil não competirá vantajosamente na África com os mesmos valores e procedimentos de potências mais capazes do ponto de vista tecnológico e industrial.

A busca de um posicionamento favorável entre os países africanos é uma necessidade indiscutível, mas, antes de tratar da presença brasileira na África, caberia observar as condições internas para um planejamento estratégico da defesa do Atlântico Sul.

Neste espaço, o maior desafio posto à atuação do Brasil é a superação da mentalidade colonial que caracteriza suas elites políticas, econômicas, intelectuais e militares. Não ocorre ao colonizado o estabelecimento de inciativas de defesa visando à busca de autonomia efetiva.

Essas elites resistem à redução das profundas desigualdades internas herdadas do passado escravista, persistem de olhos voltados para as metrópoles europeias e para os Estados Unidos, rejeitam propostas de aproximação com os vizinhos sul-americanos e veem a África como um mundo distante e sem perspectivas promissoras. A forma de pensar dessa elite é cotidianamente revelada por suas críticas aos esforços de redução das desigualdades internas e às orientações de política externa, adotadas na última década. Se a mentalidade colonial das elites civis é ostensivamente demonstrada, a percepção da cultura militar necessita de olhar mais atento. Aparentemente, as Forças Armadas hoje estão mais abertas à aproximação com a África. Escolas militares brasileiras, 
inclusive, passaram a receber um número crescente de alunos africanos.

Contudo, atentemos para a autoimagem das corporações: tanto a Marinha quanto o Exército insistem em cultivar suas origens coloniais. O receio de reformas sociais e o apego ao modelo de sociedade dos países desenvolvidos são explicitados, através do anticomunismo intransigente. Os movimentos sul-americanos em defesa de reformas sociais e de novos alinhamentos internacionais são mal vistos nas casernas. Com tal mentalidade, é difícil o militar brasileiro tomar iniciativas consoantes à importância e à natureza de seu papel do outro lado do Atlântico.

Além disso, é da natureza do militar admirar os que detêm a força. As corporações militares brasileiras persistem demasiado dependentes da produção dos países industrializados. Durante a ditadura militar, os oficiais voluntariosamente projetaram uma indústria de defesa, esquecendo que sua viabilidade dependeria de investimentos permanentes e, sobretudo, da existência de consumidores externos, conquistados por laços de cumplicidade forjados paulatinamente. A presença brasileira na África e a aproximação com os vizinhos sul-americanos teriam ajudado a manter a capacidade da indústria brasileira de defesa.

Para jogar como ator soberano, o Estado brasileiro precisa reformar em profundidade seu aparelho militar de maneira que retrate os desígnios da sociedade, superando o seu conservadorismo e os traços da cultura colonial-escravista. Como admitir que o serviço militar obrigatório persista, conduzindo os mais pobres aos quartéis e poupando os mais aquinhoados?

No que diz respeito ao desenvolvimento tecnológico, a busca da autonomia está mais voltada para os acordos com potências industriais do que para parcerias com instituições nacionais, capazes de desenvolver conhecimento próprio. Trata-se de um caminho mais longo e difícil, mas, sem dúvida, o mais sólido e promissor.

O Brasil dispõe de um sistema acadêmico de certo porte, sobretudo devido aos investimentos realizados na última década. Entretanto, são limitadas e pontuais as parcerias mantidas com as Forças Armadas. O mundo acadêmico brasileiro certamente 
Manuel Domingos Neto

responderá com vigor às demandas em matéria de pesquisa e experimentação, embora o país careça de uma agência de fomento especializada em pesquisa de material de defesa. Projetos de interesse das Forças Armadas brasileiras poderiam ser desenvolvidos em parceria com países africanos. Se a defesa do Atlântico Sul depende diretamente da colaboração com a África, é de interesse do país o desenvolvimento da capacidade técnica e científica dos africanos.

A participação do militar brasileiro em missões de paz na África também representa uma excelente oportunidade de acumular conhecimento sobre o continente, além de alimentar boas relações e cultivar uma imagem positiva do Brasil. O aprendizado nestas missões carece de sistematização e ampla difusão na sociedade brasileira.

Finalmente, a defesa do Atlântico Sul depende da inclusão das Forças Armadas em múltiplas atividades voltadas para o estreitamento das relações do Brasil com os países africanos.

A atuação brasileira pode contribuir para desfazer os laços que reservaram o imenso espaço africano aos desígnios imperialistas. Neste sentido, o estreitamento das relações políticas com os Estados africanos é irrecorrível, mas, para efeito, o primeiro e decisivo passo é a superação da mentalidade colonizada das elites brasileiras.

\section{REFERÊNCIAS}

ANDERSON, B. Os militares e a nação. Tensões Mundiais, Fortaleza, v. 07, n.12, p. 15 - 22, 2011.

DOMINGOS NETO, M. O militar e a civilização. Tensões Mundiais, Fortaleza, v. 01, n. 01, p. $37-70,2005$.

GALEANO, E. Nossos diferentes medos. La Insignia. 2001. Disponível em: <http://www.lainsignia.org/2001/abril/cul_022. htm>. Acesso em: 04 out. 2016. 